\title{
Psychosocial Well-Being Indicators of Pregnant Women of the Ethnic Mexican Teenek
}

\author{
RA Castillo-Reyther ${ }^{1,2}$, SI Lara-Rodriguez ${ }^{1}$, M Galarraga-Robledo ${ }^{1}$, J Lumbreras-Marquez ${ }^{1}$, M Barraza- \\ Salas $^{3}$, YI Hernandez-Rayon ${ }^{4}$ and F Vazquez-Alaniz ${ }^{5 *}$
}

${ }^{1}$ Gynecology \& Obstetric Department, Central Hospital "Dr. Ignacio Morones Prieto", Mexico

${ }^{2}$ Medicine Faculty, Autonomous University of San Luis Potosi, Mexico

${ }^{3}$ Chemistry Sciences Faculty, Juarez University of Durango State, Mexico

${ }^{4}$ Maternal and Child Hospital, Health Ministry of Durango, Mexico

${ }^{5}$ Clinical Laboratory, General Hospital 450, Health Ministry of Durango, Mexico

*Corresponding author: Fernando Vazquez-Alaniz, PhD, Clinical Laboratory, General Hospital 450, Health Ministery of Durango, Blvd. Jose Maria Patoni \#403, El Cipres, Zip Code: 34206, Durango, Mexico, Tel: +52(618)1373321, E-mail: feralaniz1@hotmail.com

\section{Abstract}

Background: Pregnancy is a period of physiologic and physics changes in addition of cultural, social, religious and emotional influences. The type of violence during pregnancy period can be physical, sexual, emotional or psychological.

Objective: To describe patterns of sexuality, violence, depression and, satisfaction with life and form of childbirth who wants pregnant Teenek indigenous women in the Huasteca region of San Luis Potosí in Mexico.

Methods: In 31 pregnant patients indigenous with birth control in community hospital, valid surveys were conducted to evaluate violence, depression, life satisfaction, which were repeated anonymously and added sexual habits, as well as no preference about seven forms of childbirth in women pregnant of the ethnic Mexican Teenek.

Results: The mean in the scale of life satisfaction was 18.5 (Slightly dissatisfied). With respect to depression, possibly was detected in $22.5 \%$ of all, $50 \%$ teens, violence was detected in $12.9 \%$ of all, and teens were affected in $33.3 \%$. Regarding the sexual activity were observed a significant decrease in sexual desire, $51.6 \%$ and increased $6.2 \% .58 \%$ discontinued sexual activity, mostly between the first and second quarters; of these $61 \%$ is afraid to affecting pregnancy, $38 \%$ by discomfort and $16 \%$ by migration of the partner. The preference for vertical delivery was observed in $19 \%$ of women, mostly among patients older than 28 years.

Conclusions: The Mexican indigenous population is involved in transition period, which is influenced by greater and better access to services of health and education. However, young
\end{abstract}

pregnancy women suffer from violence and depression resulting in low self-esteem and low well-being. Still required to provide more information and monitoring to better psychological and social well-being perception.

\section{Keywords}

Depression, Life satisfaction, Violence, Sexuality and Childbirth form

\section{Introduction}

Pregnancy is a period of physiologic and physics changes in addition of cultural, social, religious and emotional influences. The above be able to affect the sexuality during pregnancy, usually decreasing sexual desire and the relationships during the pregnancy period [1], although, violence against women and the use of their sexual and reproductive rights has been improved in Mexico, according to the strategies of cooperation with the Pan-American Health Organization (PAHO) and the World Health Organization (WHO).

In according to WHO, the violence is the intentional use of physical force or power, threatened or actual, against oneself, or against a group or community that either results in or has a high likelihood of resulting in injury, death, physiological harm, maldevelopment or 
deprivation [2]. In 2013 WHO estimated that as many as $38 \%$ of female homicide globally were committed by male partners while the corresponding figure for men was $6 \%$ [3]. Cause of violence against women can be culturally motivated, whether in incident involves child maltreatment, youth violence, intimate partner violence or sexual violence against women or elder abuse, and the availability of weapons are used in personal violence [2].

On the other hand, the range prevalence of violence during pregnancy period is $11-18 \%$, this violence can be physical, sexual, emotional or psychological [4,5]. National violence against women survey (ENVIM by Spanish acronym) in Mexico, distribute the prevalence of violence by geographical zones: Urban (21.3\%) and Rural (23.3\%) and indigenous (16\%) [6]. The Mexican population has been distinguished for his long history of ethnic diversity. In agree with National Population Council (CONAPO by Spanish acronym) in 2015 habiting at the country 26 million of indigenous people [7]. The violence should be studied by specific conditions and populations. This permit to compare between diverse conditions and groups of women to respect a general population to know if there exist groups with major risk of suffer violence. The CONAPO report that $5 \%$ of all health service users, speak some indigenous language and them $31 \%$ declared violence by actual partner, $44 \%$ reported to have suffered violence ever in her stable partner and $60 \%$ reported had to suffer violence sometime in her life. This fact permit to conclude that women with indigenous speak are a susceptible population from violence by their couples [7]. In Mexico exist different organizations focused to vigilance the violence of pregnant women, specifically in rural and indigenous zones, because the prenatal period supposes a vulnerable time lapse characterized by major susceptibility to depress, which is a pathology more disabling in a critical period of all women the witch needed self-care and care for her baby. The prevalence of depression in pregnancy and puerperal period is around $10-20 \%$, in agree to various authors [8-10], however, little studies have been published related with indigenous women [11] and, few studies or none has been published for pregnant indigenous Mexican women. In regard to satisfaction surveys about life quality, although appear to be subjective methods, these can offer wellness, self-perception data and suggest a comparison point with other populations [12]. The main goal of this study was to know psychosocial well-being indicators of pregnant women of the ethnic Mexican Teenek during perinatal attention in a community hospital.

\section{Material and Methods}

\section{Materials (Population study)}

Fifty Teenek indigenous pregnant women from a basic community hospital of Aquismon, municipality of San Luis Potosi, Mexico were recruited to perform this study. Only 31 finished prenatal cares or remained at the place until resolution of pregnancy and puerperal period. The criteria for recruitment were Teenek pregnant women without psychiatric disorders and, without causes of associated morbidity as anemia, hypertension disorders of pregnancy, gestational diabetes and other chronic pathologies.

\section{Methods}

This Transversal and descriptive study was evaluate and accepted by scientific and ethics committee of the Central Hospital "Ignacio Morones Prieto" of San Luis Potosi, Mexico. All participants were informed about objective and later gave written informed consent to participate and, to all women to need the assistance of an interpreter to explain the purpose of the study it was provided to them.

A variety of questionnaires, oral and written, had been applied. Because a patient screened significantly affects response rates with a 12-month prevalence of intimate Partner Violence Screen (PVS). Previously, personal and demographic data were required. Later, was applied to detect intimate partner violence, we applied Conflict Tactics Scale (CTS) [13], which is considered the gold standard for measures both the extent to which partners in a dating, cohabiting or marital relationship engage in psychological attacks on each other and also their use of reasoning or negotiation to deal conflicts. Later, to evaluate prenatal or postpartum depression was performed through Edinburgh Postnatal Depression Scale (EPDS) [14]. The EPDS includes 10 short statements, in which the mother underlines which of the four possible responses are closest to how she has been feeling during the past week; another survey was a prenatal psychological evaluation performed through Diener Satisfaction with Life Scale (SWLS) [15]. The SWLS is a short 5-item instrument designed to measure global cognitive judgments of satisfaction with one's life. All of these questions are closed-ended with yes-no or short responses. In addition, there is a verbal, less structured patient-centered approach that involves picking up on verbal and nonverbal cues, such as a patient comment about violence, a chronic pain complaint, or other issue with questions can be framed using the patient's own description, as an example: You have described a lot of violence. How is that handled at home? Finally, we annexed a page that contain images about diverse forms of delivery, including 3 vertical positions, (sitting, squatting and standing) Sims position, Gaskin position, lithotomy, as well as, caesarean with a descriptive note under the image and the pregnant women selecting the preferred option for her resolution partum in agree with model of attention to women during pregnancy, birth and puerpery; recommended by the Health Ministry in Mexico [16]. On the other hand, other anonymous and self-survey the clinic and anthropometric data with the same questions about scales for depression, violence and well-being was done to compare answers with 
opening survey. Further, self-survey includes questions about sexual habits during pregnancy, modifications about sexual desire, frequency and type of sexual contact during pregnancy and sexual practice more pleasant at the end the survey it was deposited in a close urn to guarantee confidentiality. All surveys were done the author and a bilingual community nurse with the same ethnic race.

Statistical analysis was performed using the software Minitab $^{\circledR}$ V15 (Minitab Inc. Quality Plaza, 1829 Pine Hall Road, State College, Pennsylvania) continuous and no continuous variables as depression, violence and life satisfaction, and sexual habits was performed descriptive analysis to report media, median, frequency, standard deviation and/or interquartile ranges. The categorical variables were expressed by percentage. Analysis to determine the difference between two groups for small samples with no parametric distribution was performed by Mann-Whitney $U$ test. For all analysis a $p$-value less than 0.05 was considered to be statistically significant.

\section{Results}

During two years follow-up we studied psychosocial well-being indicators of thirty-one women pregnant of the ethnic Mexican Teenek. Originally 50 women were enrolled, however, nineteen did not complete follow-up due to migration or because there solution of their pregnancy occurred in another health unit and it was not possible to conduct psychosocial satisfaction surveys. Table 1 shown demographic characteristic for participants. The principal demographic findings were a media age $24.6 \pm 6.2$ Standard Deviation (SD) years, median gestational age 25.1 (20.2-32.3 interquartile range)

Table 1: Demographic characteristics of Mexican Teenek pregnant women.

\begin{tabular}{|l|l|l|}
\hline Characteristic & Value & Range \\
\hline Maternal age (years) & 24.6 & $6.24^{¥}$ \\
\hline Gestational age (weeks) & 25.1 & $20.2-32.3^{\S}$ \\
\hline Number of pregnancies & 2 & $1.0-3.0^{\S}$ \\
\hline Beginning sexual life (years) & 17.2 & $2.49^{¥}$ \\
\hline Sexual partners & 1 & - \\
\hline Marital status & \multicolumn{2}{|l|}{} \\
\hline Single women (\%) & 22 & - \\
\hline Married women (\%) & 16 & - \\
\hline Free union (\%) & 61 & - \\
\hline Educational level (years) & 7.2 & $3.8^{¥}$ \\
\hline Religious practice & \multicolumn{2}{|l|}{} \\
\hline Catholic (\%) & 96 & - \\
\hline Evangelic (\%) & 4 & - \\
\hline
\end{tabular}

₹Standard deviation; §Interquartile range (Q1-Q3). years, the principal marital status was a free union 19 (61\%) and, only 1 (3.1\%) reported a religious practice different to catholic, the range for pregnancies was two, and only three women have a previous caesarean and eight they had their first pregnancy. The educational level was 7.2 years that include basic and media basic education.

In relation to depression, we found seven women with depression to corresponded $22.5 \%$, this result was found in both open and closed surveys. Respect to well-being indicators (Table 2) we found that the score to a diagnosis of depression was $7.35 \pm 4.1$ SD for anonym survey and $7.12 \pm 4.14$ SD for open survey without a statistical difference $(p=0.541)$. We only found a woman with a score different to "cero" for question 10 , related to self-injury thinking, this result required to do immediate additional evaluations by psychiatry department, and she was transferred to a second level to receive attention. Conflict tactics scale survey detects physical and/or emotional violence during the last year or during pregnancy. The violence was detected in $5(16 \%)$ women for both open and closed surveys. After women were identified, they were conducted to the social work department to offer orientation to guide to accept all possible support. It is important to emphasize that all universe study, $6(19.3 \%)$ were adolescents $(<18$ years) 2 (33\%) suffered violence and $3(50 \%)$ presented depression. Respect to Diener SWLS the median score was 18.3 \pm 3.78 SD in non-anonymous survey and, $18.5 \pm 3.36$ SD in a closed survey without statistical difference between surveys $(p=0.875)$. With respect to partum preferences, a 21 (67.7\%) preferred lithotomy position and traditional form (vertical position) in this ethnic group had a $7(22.5 \%)$ of preference of these, $2(6.2 \%)$ women preferred a sitting position and 1 preferred squatting in position and, $2(6.2 \%)$ preferred caesarean. Important to say that 5 women with a $>28$ years were previously attended by traditional midwife in other pregnancies. Surprisingly, when we asked if they preferring support of a relative $29(93 \%)$ answered yes and, $24(77.4 \%)$ of they selected to partner and rest, to their mother. Related to sexual practices with more satisfaction they reported first the kisses $27(83.8 \%)$, second vaginal sex 10 (32.2\%) and, sexual fantasies 10 (32.2\%), other practices are reported in Table 3. The frequency with respect to sexual contact $18(58 \%)$ suspended all sexual contact but, $9(50 \%)$ of their woes have sexual contact. Most of them suspend sexual activity between first and second trimester referring fear to damage to baby in 20 (61\%), discomfort during pregnancy in $10(31 \%)$, with a less

Table 2: Well-being indicators of Mexican Teenek pregnant women.

\begin{tabular}{|l|l|l|l|l|l|}
\hline Parameter of well-being & $\mathbf{n}$ & Cases (\%) & Adolescent (\%) & Anonymous survey & Open survey \\
\hline Depression $^{1}$ & 31 & $7(22.5)$ & $3(50)$ & $7.35 \pm 4.74$ & $7.12 \pm 4.41$ \\
\hline Violence $^{2}$ & 31 & $4(12.9)$ & $2(33.3)$ & $7.35 \pm 4.73$ & $7.12 \pm 4.14$ \\
\hline Well-being of life $^{3}$ & 31 & - & - & $18.3 \pm 3.78$ & $18.5 \pm 3.36$ \\
\hline
\end{tabular}

${ }^{1}$ Edinburgh scale; ${ }^{2}$ Conflict tactics scale; ${ }^{3}$ Diener scale. 
Table 3: Sexual practices with more pleasure.

\begin{tabular}{|l|l|l|}
\hline Sexual practice & Number & Percentage (\%) \\
\hline Fantasies & 6 & 19.3 \\
\hline Kisses & 26 & 83.3 \\
\hline Masturbation & 1 & 3.2 \\
\hline Sexual play & 2 & 6.4 \\
\hline Caresses on the breast & 5 & 16.1 \\
\hline Vaginal penetration & 10 & 32.2 \\
\hline Anal sex & 0 & 0 \\
\hline Oral sex & 1 & 3.2 \\
\hline
\end{tabular}

Table 4: Primary changes in sexual habits.

\begin{tabular}{|l|l|l|}
\hline Sexual habits & Yes (\%) & No (\%) \\
\hline Sexual desire modification & $18(58.1)$ & $13(41.9)$ \\
\hline Increased desire & $16(51.6 \%)$ & - \\
\hline Decreased desire & $2(6.4 \%)$ & - \\
\hline Equal (remains the same) & $13(42 \%)$ & - \\
\hline Satisfactory sexual contact & $21(67.7 \%)$ & $10(33.3 \%)$ \\
\hline Orgasms & $18(58 \%)$ & - \\
\hline Desire for sexual contact & $18(58.1 \%)$ & $13(41.9 \%)$ \\
\hline Interrupted & $9(29 \%)$ & $9(29 \%)$ \\
\hline Not interrupted & $9(29 \%)$ & $4(12.9 \%)$ \\
\hline
\end{tabular}

proportion by partner migration and, only $15(42 \%)$ did not suspend sexual contact but, reduced frequency 2-4 times per week to only once per week. In the survey, we ask if her partner suggested sexual contact in good manner, $28(90 \%)$ answered yes and, $3(10 \%)$ reported that they took the initiative. 7 (22.5\%) of women reported a change in sexual conduct by partner, because they have fear to damage the baby.

Related to sexual desire (Table 4), we observed a modification in 18 (58\%) women, decreased desire in 9 (51\%) of their, increased desire in $2(6.2 \%)$ and, remained equal to 8 (41.9\%). 22 (67.7\%) referred satisfaction during sexual contact and $18(58 \%)$ referred orgasms or the best satisfaction. In Relation to discomfort during sexual contact, 18 (58\%) referred abdominal pain, $8(25.8 \%)$ vaginal pain, $8(25.8 \%)$ vaginal infection, and $5(16 \%)$ no reported changes.

\section{Discussion}

The non-fatal consequences of violence are by far the greatest part of the social and health burden arising from violence. Physical injuries themselves are outweighed by the wide spectrum of negative behavioral, cognitive, mental health, sexual and reproductive health problems, chronic diseases and social effects that arise from exposure to violence. All types of violence have been strongly linked to negative health consequences across the lifespan, but violence against women and children contributes disproportionately to the health burden. The available evidence shows that victims of child maltreatment and women who have experienced intimate partner and sexual violence have more health problems, incur significantly higher health care costs, make more visits to health providers over their lifetimes and have more hospital stays than those who have not experienced violence [2]. On the other side, indigenous women are a growing segment of the population of women giving birth. Overall, they experience more risk factors for mental health problems than non-indigenous women and a larger proportion of their experience mental health problems during pregnancy and postpartum. However, the dearth of detailed information about the mental health problems of Indigenous demands rigorous, longitudinal studies that primarily explore depression, anxiety or mood problems and positive mental health. A previous study has reported an unfavourable structural condition in which Mexican indigenous life constitutes the persistence mechanisms of their health vulnerability and recommend an intensive an a focalized health strategy contribute to improve their health condition and life [17]. Now, we demonstrate that an effective and efficient health services and opportune access to antenatal care in indigenous communities to be decrease no planned pregnancies as well as reduce a high score of adolescent pregnancy. Another factor envolved in improving the quality of life in pregnant women has been implementation of programs as "opportunities" [18] focused to better cognitive and non-cognitive abilities as well as promote the access to education since many years ago, although at the level of education of our study group it is basic, if there are differences from completely isolated groups where access to education does not exist or is minimal. On the other hand, free union as marital status appear as the traditional form the partnership between this and other ethnic groups in Mexico [19]. The preference for mating between same members' ethnic group is influenced by parents and we consider an important factor to underlying a positive attitude toward controlling the mate choice of one's offspring under their traditional customs and similar social characteristics were observed in other Mexican ethnical groups by Abraham P Buunk, et al. [19]. Frequency of possible depression found in women pregnant of the ethnic Mexican Teenek with 10 or greater score in EPDS scale was 7 (22.5\%), so much higher than reported by Gavin N, et al. [20] in meta-analysis study (12.9\%) in women at different trimesters of pregnancy and months in the first postpartum year, but slightly higher than frequency founded by Galvez, et al. (20.6\%) for urban and rural population in our locality, remarking a high prevalence in adolescent women (data not published). Victims of violence are also at higher risk of depression, anxiety, post-traumatic stress disorder and suicidal behaviour [21]. Both exposures to violence and men's perpetration of violence against women have been shown to be associated with high-risk sexual behaviours [2].

High frequency of depression has so much relevance because have a high impact difficulty habitual activity of pregnant women as bad dietetic habits, alter cycle sleep, poor adherence in antenatal care, high risk to herself-injury, including suicide [22-24]. Violence during 
pregnancy has been associated with adverse pregnancy outcomes, such as low birth weight, premature labour, preterm delivery, miscarriage, and foetal injury [25]. In developed countries as Sweden the prevalence of domestic violence during pregnancy, irrespective of type or severity was reported by $2.5 \%$ [26]. In North America, most estimates of prevalence of such violence fall between $4 \%$ and $8 \%$ [27]. In developing countries, these rates are estimated to be as high as 32\% [28]. In our study, we found the violence frequency with a score between 2-5 (suffer violence 2-5 times in the past year) of $5(16.1 \%)$ and did not find studies that refer to violence in indigenous pregnant women to compare. The value $(18.3 \pm 3.78 \mathrm{SD})$ of the life scale satisfaction is related to people who usually have small but significant problems in several areas of their lives, or have many areas that are doing fine but one area that represents a substantial problem for them [15]. In context with sexual habits the main finding was that women and their partners used to avoid sexual contact in the first trimester because is afraid to affecting the baby, then some women remarked that they will avoid soon for preventing damage the baby. So fact, many simultaneous physiological and psychological factors affect the sexual expression of the couples. Sexual fluctuations are a natural phenomenon during the transition to parenthood; couples must adjust to the new conditions and to the changes associated with sexuality during pregnancy, which are considered seasonal [29] and, Afrakoti NB, et al. [30] classified these factors as biological, psychological and social factors. Meanwhile, Rivas RE, et al. [31] found that the frequency of sexual activity declined progressively during pregnancy compared with pre-pregnancy levels, with a partial recovery six months after childbirth. May be these changes promote other forms of sexual expression and, in this context, the Teenek women mentioned caresses, kisses and, fantasies as complement on relation with her partners with a view to sexual well-being in general. On this fact, de Pierrepont, et al. [32] said that promoting the health and well-being of the couple, the child, the family and society, the perinatal gender intervention should be part of the health surveillance of women to help maintain a positive relationship in terms of intimacy and sexuality in the couple. Traditionally, indigenous women gave birth in their communities. Cultural practices established strong community roots for the mother, her infant, and the family and, the children born in the community developed a clear sense of identity that helped them to become resilient and responsible members of that community [33]. In our study, the preference on relation with form childbirth highlight a clear influence between midwife attention some years ago and attention in community hospitals to date and, with preference of lithotomy position on traditional childbirth (vertical), only three women over of 28 year of age request traditional childbirth. May be because Nurses with the same ideology and costumes can also promote indigenous women to pursue careers in health care [34].

\section{Conclusions}

Indigenous population in Mexico is coursing by transition period, influencing by most and better access to health care services and education programs, However, it is necessary to get more information to establish protocols to permit, detect and support to all pregnant women victims of violence and, depression especially those with psychiatric comorbidities and putting more attention on adolescent pregnant women. Still required to provide more information and monitoring to better psychological and social well-being perception. In addition, we consider it important that medical care personal goes back to humanity's labor, focusing on psychoactive areas to detect those psychiatric red flags framed by the lack of confidence towards health care professionals. Due to the diverse forms of childbirths, it is determinant that health care personal, takes appropriate training to promote and respect the right of indigenous pregnant women to choose.

\section{Acknowledgements}

We acknowledge and thank To Mario Adolfo Huerta-Aguilar, Medical Director in basic community hospital of Aquismón, SLP, Mex for giving us facilities to realize this project and, Estela Hernández-Martinez; Nurse of the basic community hospital, for your personal assistance in survey's and interprets Teenek language.

This work was supported by Health Ministry of San Luis Potosi, Mex. and Health Ministry of Durango. Mex.

\section{Ethical Statement}

This study was evaluate and accepted by scientific and ethics committee of the Central Hospital "Ignacio Morones Prieto" of San Luis Potosi, Mexico.

\section{Conflict of Interest Statement}

The authors report no declarations of interest.

\section{References}

1. Bartellas E, Crane JM, Daley M, Bennett KA, Hutchens D (2000) Sexuality and sexual activity in pregnancy. BJOG 107: 964-968.

2. World Health Organization (2014) Global status report on violence prevention. Geneva, Switzerland.

3. Howes P (2013) Global and regional estimates of violence against women: prevalence and health effects of intimate partner violence and non-partner sexual violence. World Health Organization Geneva, Switzerland.

4. Mahenge B, Stockl $H$, Abubakari A, Mbwambo J, Jahn A (2016) Physical, sexual, emotional and economic intimate partner violence and controlling behaviors during pregnancy and postpartum among women in dar es salaam, Tanzania. PLoS One 11: e0164376.

5. Jackson CL, Ciciolla L, Crnic KA, Luecken LJ, Gonzales NA, et al. (2015) Intimate partner violence before and 
during pregnancy: related demographic and psychosocial factors and postpartum depressive symptoms among Mexican American women. J Interpers Violence 30: 659-679.

6. Olaiz G, Uribe P, Del Rio A (2009) Encuesta nacional sobre violencia contra las mujeres 2006. DF: Secretaria de Salud, Mexico.

7. (2014) Infografia poblacion indigena. Consejo Nacional de Poblacion, Mexico.

8. Salm Ward T, Kanu FA, Robb SW (2017) Prevalence of stressful life events during pregnancy and its association with postpartum depressive symptoms. Arch Womens Ment Health 20: 161-171.

9. Bruggmann D, Wagner C, Klingelhofer D, Schoffel N, Bendels M, et al. (2017) Maternal depression research: socioeconomic analysis and density-equalizing mapping of the global research architecture. Arch Womens Ment Health 20: 25-37.

10. Fairbrother N, Janssen $\mathrm{P}$, Antony MM, Tucker E, Young $\mathrm{AH}$ (2016) Perinatal anxiety disorder prevalence and incidence. Journal of Affective Disorders 200: 148-155.

11. Bowen A, Duncan V, Peacock S, Bowen R, Schwartz L, et al. (2014) Mood and anxiety problems in perinatal Indigenous women in Australia, New Zealand, Canada, and the United States: a critical review of the literature. Transcult Psychiatry 51: 93-111.

12. Caballero Martinez M, Richart Martinez M, Cabrero Garcia J, Orts Cortez M, Reig Ferrer A, et al. (2004) Fiabilidad y validez de la escala de satisfaccion con la vida de Diener en una muestra de mujeres embarazadas y puerperas. Psicothema 16: 448-455.

13. Porcerelli JH, Cogan R, Kamoo R, Leitman S (2004) Defense mechanisms and self-reported violence toward partners and strangers. Journal of Personality Assessment 82: 317-320.

14. Cox JL, Holden JM, Sagovsky R (1987) Detection of postnatal depression. development of the 10-item edinburgh postnatal depression scale. Br J Psychiatry 150: 782-786.

15. Diener E, Emmons RA, Larsen RJ, Griffin S (1985) The satisfaction with life scale. J Pers Assess 49: 71-75.

16. Almaguer-Gonzalez J, Garcia-Ramirez H, Vargas-Vite V, Pimienta-Luna F (2008) Modelo de atencion a las mujeres durante el embarazo, parto y puerperio: Enfoque humanizado, intercultural y seguro, DF: Secretaria de Salud, Mexico.

17. Servan-Mori E, Pelcastre-Villafuerte B, Heredia-Pi I, Montoya-Rodriguez A (2014) Essential health care among Mexican indigenous people in a universal coverage context. Ethn Dis 24: 423-430.

18. Figueroa JL (2014) Distributional effects of oportunidades on early child development. Soc Sci Med 113: 42-49.

19. Buunk AP, Pollet TV, Dubbs S (2012) Parental control over mate choice to prevent marriages with out-group members: a study among mestizos, Mixtecs, and Blacks in Mexico. Human Nature 23: 360-374.

20. Gavin NI, Gaynes BN, Lohr KN, Meltzer-Brody S, Gartlehner G, et al. (2005) Perinatal depression: a systematic review of prevalence and incidence. Obstet Gynecol 106: 1071-1083.

21. Andrews G, Corry J, Slade T, Issakidis C, Swanton H (2004) Child sexual abuse. In: Ezzati M, Lopez A, Rodgers A, Murray $C$, Comparative quantification of health risks: Global and regional burden of disease attributable to se- lected major risk factors. WHO press, Geneva, Switzerland, 1851.

22. Baiardi S, Cirignotta F, Cicolin A, Garbazza C, D'Agostino A, et al. (2016) Chronobiology, sleep-related risk factors and light therapy in perinatal depression: the "Life-ON" project. BMC Psychiatry 16: 374.

23. Paliy O, Piyathilake CJ, Kozyrskyj A, Celep G, Marotta F, et al. (2014) Excess body weight during pregnancy and offspring obesity: potential mechanisms. Nutrition 30: 245251.

24. Gelaye B, Kajeepeta S, Williams MA (2016) Suicidal ideation in pregnancy: an epidemiologic review. Arch Womens Ment Health 19: 741-751.

25. Gazmararian JA, Petersen R, Spitz AM, Goodwin MM, Saltzman LE, et al. (2000) Violence and reproductive health: current knowledge and future research directions. Maternal and Child Health Journal 4: 79-84.

26. Finnbogadottir H, Dykes AK (2016) Increasing prevalence and incidence of domestic violence during the pregnancy and one and a half year postpartum, as well as risk factors: A longitudinal cohort study in Southern Sweden. BMC Pregnancy and Childbirth 16: 327.

27. Martin SL, Mackie L, Kupper LL, Buescher PA, Moracco KE (2001) Physical abuse of women before, during, and after pregnancy. JAMA 285: 1581-1584.

28. Campbell J, Garcia-Moreno C, Sharps P (2004) Abuse during pregnancy in industrialized and developing countries. Violence Against Women 10: 770-789.

29. de Pierrepont C, Polomeno V, Bouchard L, Reissing E (2016) What do we know about perinatal sexuality? A scoping review on sexoperinatality - part 1. J Gynecol Obstet Biol Reprod (Paris) 45: 796-808.

30. Afrakoti N, Shahhosseini Z (2016) Bio-Psycho-Social factors affecting women's sexual function during pregnancy: A narrative review. Glob J Health Sci 8: 55246.

31. Rivas RE, Navio JF, Martinez MC, Miranda Leon MT, Castillo RF, et al. (2016) Modifications in sexual behaviour during pregnancy and postpartum: Related factors. The West Indian Medical Journal.

32. de Pierrepont C, Polomeno V, Bouchard L, Reissing E (2016) What do we know about perinatal sexuality? A scoping review on sexoperinatality - Part 2. J Gynecol Obstet Biol Reprod (Paris) 45: 809-820.

33. (2010) Returning birth to aboriginal, rural, and remote communities. J Obstet Gynaecol Can 32: 1186-1188.

34. Varcoe C, Brown H, Calam B, Harvey T, Tallio M (2013) Help bring back the celebration of life: a community-based participatory study of rural Aboriginal women's maternity experiences and outcomes. BMC Pregnancy and Childbirth 13: 26. 